\title{
Is There Any Difference Between Depression and Anxiety in Overactive Bladder According to Sex? A Systematic Review and
} Meta-Analysis

\author{
Iane Glauce R Melotti ${ }^{1}$, Cássia Raquel Teatin Juliato ${ }^{2}$, Suelene Costa de Albuquerque Coelho ${ }^{3}$, Marcelo Lima ${ }^{4}$, \\ Cassio Luiz Zanettini Riccetto ${ }^{5}$ \\ ${ }^{1}$ School of Medicine, University of Campinas (UNICAMP), Campinas, Brazil \\ ${ }^{2}$ Department of Obstetrics and Gynecology, School of Medicine, University of Campinas (UNICAMP), Campinas, Brazil \\ ${ }^{3}$ School of Medicine, University of Campinas (UNICAMP), Campinas, Brazil \\ ${ }^{4}$ Department of Obstetrics and Gynaecology, State University of Campinas (UNICAMP), Campinas, Brazil \\ ${ }^{5}$ Department of Surgery, School of Medicine, University of Campinas (UNICAMP), Campinas, Brazil
}

Purpose: Overactive bladder $(\mathrm{OAB})$ is characterized by urinary urgency with or without urge incontinence, accompanied by frequency and nocturia. It affects individuals of all ages and can predispose affected individuals to depression and anxiety. However, few studies have been conducted on this topic. The objective of this study was to perform a systematic review and meta-analysis assessing the symptoms of depression, anxiety, and OAB using validated instruments.

Methods: The search for articles was based on the following descriptors: overactive bladder, depression, and anxiety ("Urinary bladder, Overactive AND Depression and Anxiety") OR ("Urinary bladder, Overactive AND Depression" OR "Urinary bladder, Overactive AND Anxiety"). The databases searched included PubMed, MEDLINE, and SciELO.

Results: Initially, 111 articles were identified, but only 11 articles, containing 11,784 participants with depression and 10,436 with anxiety, specifically addressed depression or anxiety and were included in this systematic review. Ten articles incorporated a quantitative analysis, with cohort, series, population-based, and cross-sectional designs. One qualitative study was also included. Three articles were included in the meta-analysis, resulting in a total of 7,468 participants in whom depression was evaluated and 8,030 participants in whom anxiety was analyzed. Depression and anxiety were positively correlated with OAB. Men with OAB were considerably more likely than women to have anxiety (odds ratio [OR], 1.56; 95\% confidence interval $[C I], 1.40-1.73)$ but there was no sex-related difference in depression (OR, 0.96; 95\% CI, 0.77-1.21).

Conclusions: This study showed a positive correlation between $\mathrm{OAB}$ and anxiety and depression. Men were considerably more likely than women to have anxiety related to $\mathrm{OAB}$, but depression levels in $\mathrm{OAB}$ patients were not sex-related. This review highlights the need to investigate depression and anxiety in patients with $\mathrm{OAB}$.

Keywords: Urinary Bladder, Overactive; Depression; Anxiety; Quality of Life; Review

- Conflict of Interest: No potential conflicts of interest relevant to this article were reported.

\section{- HIGHLIGHTS}

- There was a positive correlation between $O A B$ and anxiety/depression.

- Men had more anxiety related to $O A B$, but depression in $O A B$ patients was not sex-related.

- This review highlights the need to investigate depression and anxiety in patients with $O A B$.

Corresponding author: Cássia Raquel Teatin Juliato

(i) https://orcid.org/0000-0003-3197-1195

Department of Gynecology and Obstetrics, University of Campinas (UNICAMP),

Rua Alexander Fleming, 101, Cidade Universitária Zeferino Vaz, Campinas, São

Paulo13083-881, Brazil

E-mail: cassia.raquel@gmail.com / Tel and Fax: +55-19-35219306

Submitted: April 12, 2017 / Accepted after revision: August 13, 2017
This is an Open Access article distributed under the terms of the Crecc)
commons.org/licenses/by-nc/4.0/) which permits unrestricted non-commercial use, distribution, and reproduction in any medium, provided the original work is properly cited. 


\section{INTRODUCTION}

Overactive bladder $(\mathrm{OAB})$ was defined by the International Continence Society and International Urogynecological Association in 2002 and 2010, respectively, as a syndrome characterized by urgency with or without urge incontinence, usually accompanied by urinary frequency and nocturia, in the absence of lower urinary tract infection or other diseases [1,2], that significantly affects quality of life [3]. Studies conducted in the United States have characterized OAB as a highly prevalent condition that affects $16.9 \%$ of the female population [3-5].

Voiding symptoms can be responsible for the onset or exacerbation of problems with the social, psychological, emotional, and sexual aspects of quality of life [6]. Impairment of affective aspects and mood are commonly identified in $\mathrm{OAB}$ patients, but it is estimated that almost half of women with $\mathrm{OAB}$ do not receive appropriate treatment for their psychologic concerns [4]. Depression and anxiety are classified as affective disorders according to the diagnostic criteria of the Diagnostic and Statistical Manual of Mental Disorders, 4th edition, and both of them have been reported to be common in OAB patients [7].

Anxiety is often associated with new and unknown situations, which is a characteristic of most illnesses, and depression can be confused with an underlying organic disease, since pain and functional disability can elicit symptoms commonly associated with depression, such as insomnia, irritability, anhedonia, low self-esteem, fatigue, and loss of libido [8].

Faced with the considerable repercussions of OAB in peoples' lives, there is a consensus that it is necessary to investigate the prevalence of depression and anxiety in patients with $O A B$. Understanding the relationship of $\mathrm{OAB}$ with depression and anxiety can help doctors to propose therapeutic strategies to support patients as they emotionally cope with their condition.

The purpose of this systematic review and meta-analysis was to evaluate the correlations of depression and anxiety with symptoms of $\mathrm{OAB}$, with a particular focus on whether such correlations were affected by sex.

\section{MATERIALS AND METHODS}

\section{Instruments for Data Collection}

The search for articles was based on Medical Subject Headings descriptors, which included ("Urinary bladder, Overactive AND Depression and Anxiety") OR ("Urinary bladder, Overactive AND Depression" OR "Urinary bladder, Overactive

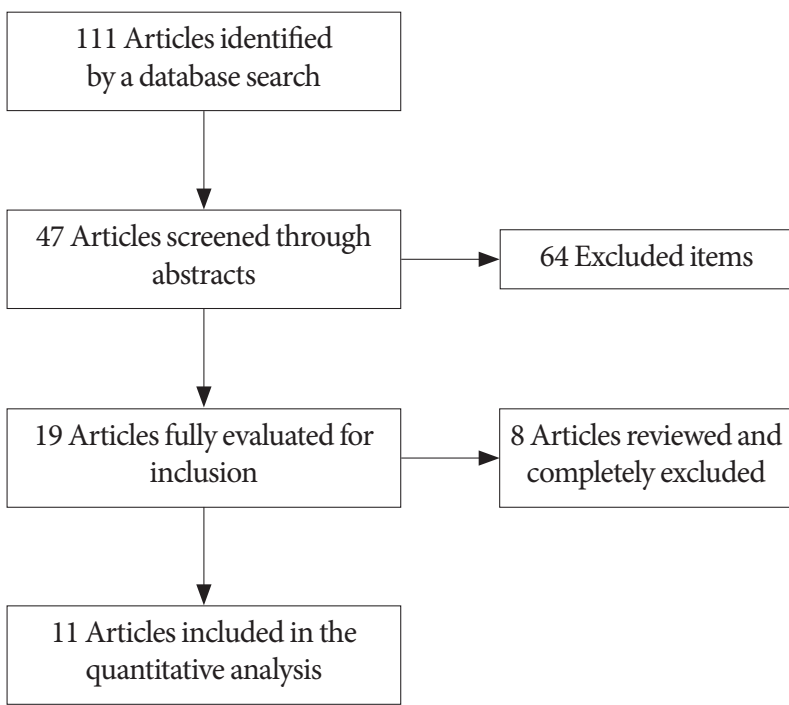

Fig. 1. Flowchart of the study according to the guidelines of the PRISMA (Preferred Reporting Items for Systematic Reviews and Meta-Analyses) statement.

\section{AND Anxiety").}

The search strategy was designed for the PubMed database, and was modified for use in the MEDLINE and SciELO databases. The results were first screened by reading the titles, abstracts, and finally, the full text of the studies. The reference lists of the included studies were searched manually. Data collection was conducted independently and blindly by 2 researchers (IGRM and SCAC) and was reviewed by another researcher (CRTJ), strictly observing the inclusion criteria. A flowchart was created in accordance to the guidelines of the Preferred Reporting Items for Systematic Reviews and Meta-Analyses (PRISMA) statement (Fig. 1).

The inclusion criteria were studies that used validated instruments to assess the presence of depression and/or anxiety correlated to OAB. Only articles in English were selected, with no limit on the publication year. The exclusion criteria were systematic reviews, articles related to drugs for the treatment of $\mathrm{OAB}$, those analyzing other comorbidities related to $\mathrm{OAB}$, and articles that were not appropriate. Quality control was guaranteed by an independent and blind evaluation by 2 researchers (IGRM and SCAC), who decided which studies were eligible to be included in the systematic review. After this initial screening, the Jadad score was calculated for all articles [9], and only papers for which the Jadad score was greater than 2 were ultimately included.

Outcomes (depression and anxiety assessed by the same in- 
strument) verified in more than 2 articles were grouped for the meta-analysis. Only 3 of the 11 articles, which used the Hospital Anxiety and Depression Scale (HADS) with the same cutoffs, were included in the meta-analysis.

In the statistical analysis, the Mantel-Haenszel test was used to assess the risk ratio between the groups for outcomes measured in proportions (i.e., dichotomous outcomes). For quantitative outcomes (with averages and standard deviations), the mean difference between the groups was analyzed.

The heterogeneity between studies was assessed through the chi-square test of study homogeneity and through the I2 index, which varies from $0 \%$ to $100 \%$, where:

- $0 \%-40 \%$ : There is no significant heterogeneity.

- 30\%-60\%: There may be moderate heterogeneity.

- 50\%-90\%: There may be substantial heterogeneity

- 75\%-100\%: There is great heterogeneity across studies.

The computer system utilized was Review Manager (RevMan

5, Cochrane Collaboration, Oxford, UK) [10]. For studies with heterogeneity greater than $50 \%$ and $\mathrm{P}<0.05$, a random-effects meta-analysis was performed [11].

\section{RESULTS}

A total of 111 articles were initially identified, from which the abstracts of 47 articles were screened, resulting in 19 full-text articles that were assessed for eligibility. Eight articles were excluded because they did not meet the inclusion criteria, and 11 articles were included in the systematic analysis, with 10,436 participants in whom anxiety was evaluated (6,865 women and 3,571 men) and 11,784 participants in whom depression was evaluated (7,426 women and 4,358 men) (Table 1).

Only 1 qualitative study was included in this review [12]. The methodology of the articles included cross-sectional population-based studies [5,13-19], as well as a cohort study [20] and a prospective cohort study [21].

Table 1. Articles included in the systematic review

\begin{tabular}{|c|c|c|c|c|c|}
\hline Study & Study design & Sample size ${ }^{\text {a) }}$ & Depression & Anxiety & Intervention \\
\hline $\begin{array}{l}\text { Stewart et al., } \\
2003[5]\end{array}$ & Cross-sectional & Depression: $\mathrm{N}=397$ ( 211 women and 186 men) & $\begin{array}{l}\text { SF-36/CES-D/ } \\
\text { MOS }\end{array}$ & NA & Interview \\
\hline $\begin{array}{l}\text { Nicolson et al., } \\
2008 \text { [12] }\end{array}$ & Qualitative studies & $\begin{array}{l}\text { Anxiety and depression: } \mathrm{N}=18 \\
(10 \text { women and } 8 \text { men })\end{array}$ & Interview & Interview & Interview \\
\hline $\begin{array}{l}\text { Milsom et al., } \\
2012[13]\end{array}$ & Population-based & $\begin{array}{l}\text { Depression: } N=4,609 \text { ( } 3,078 \text { women and } 1,531 \text { men) } \\
\text { Anxiety: } N=4,557 \text { ( } 3,036 \text { women and 1,521 men) }\end{array}$ & HADS & HADS & Interview \\
\hline $\begin{array}{l}\text { Sexton et al., } \\
2011[14]\end{array}$ & Population-based & $\begin{array}{l}\text { Depression: } \mathrm{N}=2,256(1,350 \text { women and } 906 \mathrm{men}) \\
\text { Anxiety: } \mathrm{N}=2,209(1,320 \text { women and } 889 \text { men })\end{array}$ & HADS & HADS & Internet survey \\
\hline $\begin{array}{l}\text { Ikeda et al., } \\
2011[15]\end{array}$ & Cross-sectional & Depression: $\mathrm{N}=153$ ( 80 women and 73 men) & MMSE/GDS 30 & NA & Interview \\
\hline $\begin{array}{l}\text { Coyne et al., } \\
2008[16]\end{array}$ & Population-based & Depression: $\mathrm{N}=1,434$ (932 women and 502 men) & CES-D & NA & Interview \\
\hline $\begin{array}{l}\text { Irwin et al., } \\
2005 \text { [17] }\end{array}$ & Population-based & $\begin{array}{l}\text { Depression and anxiety: } \mathrm{N}=1,272 \\
\text { (732 women and } 540 \mathrm{men} \text { ) }\end{array}$ & Interview & Interview & Interview \\
\hline $\begin{array}{l}\text { Teloken et al., } \\
2006[18]\end{array}$ & Population-based & $\begin{array}{l}\text { Depression and anxiety: } \mathrm{N}=160 \\
\text { (104 women and } 56 \text { men) }\end{array}$ & $\begin{array}{l}\text { King's Health } \\
\text { Questionnaire }\end{array}$ & $\begin{array}{l}\text { King's Health } \\
\text { Questionnaire }\end{array}$ & Interview \\
\hline $\begin{array}{l}\text { Lim et al., } \\
2007[19]\end{array}$ & Population-based & Anxiety: (N=172 women) & NA & BAI & Interview \\
\hline $\begin{array}{l}\text { Alves et al., } \\
2014[20]\end{array}$ & Cohort & Anxiety: $(\mathrm{N}=166$ women $)$ & NA & BAI & Interview \\
\hline $\begin{array}{l}\text { Coyne et al., } \\
2011[21]\end{array}$ & Prospective cohort & $\begin{array}{l}\text { Depression: } N=1,485 \text { ( } 929 \text { women and } 556 \text { men) } \\
\text { Anxiety: } N=1,882 \text { ( } 1,325 \text { women and } 557 \text { men) }\end{array}$ & HADS & HADS & Interview \\
\hline
\end{tabular}

SF-36, 36-Item Short Form Survey; CES-D, Center for Epidemiologic Studies Depression Scale; MOS, Medical Outcomes Sleep Scale; NA, not applicable; HADS, Hospital Anxiety and Depression Scale; MMSE, Mini-Mental Status Examination; GDS 30, Geriatric Depression Scale; BAI, Beck Anxiety Inventory.

a) Sample size: overactive bladder population; number of men or women who answered questionnaires about depression or anxiety. 


\section{Instruments for Anxiety/Depression Assessment Used in the Articles}

Three studies used HADS to assess the severity of participants' depression and anxiety $[12,13,20]$. The Beck Anxiety Inventory (BAI) was used in 2 studies [18,19]. The Geriatric Depression Scale was applied in 1 study [14], and the Center for Epidemiologic Studies Depression Scale (CES-D) was utilized in 2 studies $[5,15]$.

Only 3 articles, which used HADS, were included in the meta-analysis $[12,13,20]$. The articles based on BAI and CES-D (2 articles each) were not included because they used different scoring values, which made comparison in the meta-analysis impossible.

\section{Assessment of Depression and Anxiety}

Six studies (6 of 11) assessed depression and anxiety by validated and specific instruments $[5,13,14,17,18,21]$. Three studies evaluated only depression and other psychological factors $[5,15,16]$, and 2 studies focused only on anxiety [16,17]. Eight articles compared participants with and without $\mathrm{OAB}[5,13$ $18,21]$. All studies showed an association between $O A B$ and higher depression and anxiety scores. OAB was associated with lower quality of life scores (36-Item Short Form Survey [SF-36]) and higher depression scores in the National Overactive Bladder Evaluation program, which studied a sample of 397 adults at least 18 years of age with $\mathrm{OAB}$ [5]. In another large population-based study, Coyne et al. [16] assessed the effects of $\mathrm{OAB}$ and other lower urinary tract symptoms on health-related quality of life in a sample of the population from the European Prospective Investigation into Cancer and Nutrition study and found that $\mathrm{OAB}$ patients reported worse scores of quality of life, higher rates of depression, and less enjoyment of sexual activity than the other subgroups of patients.

In an epidemiological study, Milsom et al. [13] determined the level of anxiety and depression associated with $\mathrm{OAB}$ and its influence on health-related quality of life. They concluded that urgency was an important predictor associated with anxiety and depression related to $\mathrm{OAB}$ for both sexes, followed by urge incontinence, frequency, and nocturia.

The correlation of OAB subtypes ('dry' or 'wet') with depression was analyzed in 4 studies $[5,12,16,17]$ and with anxiety in 2 studies [12,17]. All studies showed a relationship between urge incontinence and worse depression and anxiety scores. In a study including men and women, it was shown that regardless of urinary leakage, $\mathrm{OAB}$ was significantly associated with lower quality of life scores (SF-36), higher depression scores (CES-D), and worse sleep quality than controls [5]. In a population-based cross-sectional study including 1,434 women, higher scores on a depression questionnaire and in interviews were found in subjects with $\mathrm{OAB}$ and urge incontinence than in those without urge incontinence [16]. Additionally, a qualitative study pointed out the importance of fear of incontinence as a cause of distress in women with $\mathrm{OAB}$, concluding that its symptoms may be associated with a feeling of incompetence and stigmatization [12]. Another article showed that patients with OAB with incontinence presented emotional stress at a rate of $36.4 \%$, vs. $19.6 \%$ for those without incontinence. The reported prevalence of depression was $39.8 \%$ and $23.3 \%$ in incontinent versus continent subjects with $\mathrm{OAB}$, respectively. They concluded that $\mathrm{OAB}$ patients with urge incontinence were significantly more likely than those without incontinence to express concern about having accidents and to experience fear about participation in any activities outside of the home due to their urinary symptoms [17].

\section{$O A B$, Sex, Depression, and Anxiety}

Two studies were exclusively conducted in women with $\mathrm{OAB}$ $[19,20]$, and the other 9 studies included both sexes. Two studies $[14,15]$ focused on the relationship between psychological symptoms and $\mathrm{OAB}$ according to age (elderly people, over 65 years old).

One of these 2 studies that exclusively included women compared the degree of anxiety between women with mixed urinary incontinence (MI) and stress urinary incontinence (SUI). The assessment of anxiety was performed using the BAI questionnaire and the difference was statistically significant, leading the authors to conclude that MI patients had a higher degree of anxiety than those with pure SUI [19]. The other study evaluated 166 women with $\mathrm{OAB}$ in order to establish correlations with mental distress in this subset of patients, and they concluded that the anxiety in this group of women may have been due to the presence of urinary symptoms or vice versa [20].

Teloken et al. [18] assessed the prevalence of OAB in a Brazilian population-based study. The overall prevalence of $\mathrm{OAB}$ was $18.9 \%$. OAB was more prevalent in women, except $\mathrm{OAB}$ without urge incontinence, which was more common in men than in women. Individuals with $\mathrm{OAB}$ presented a higher prevalence of depression, anxiety, shame, and fatigue. $\mathrm{OAB}$ was independently associated with impairments in individuals' sexual life (OR, 3.36; 95\% CI, 1.20-9.39). In women, the prevalence of 


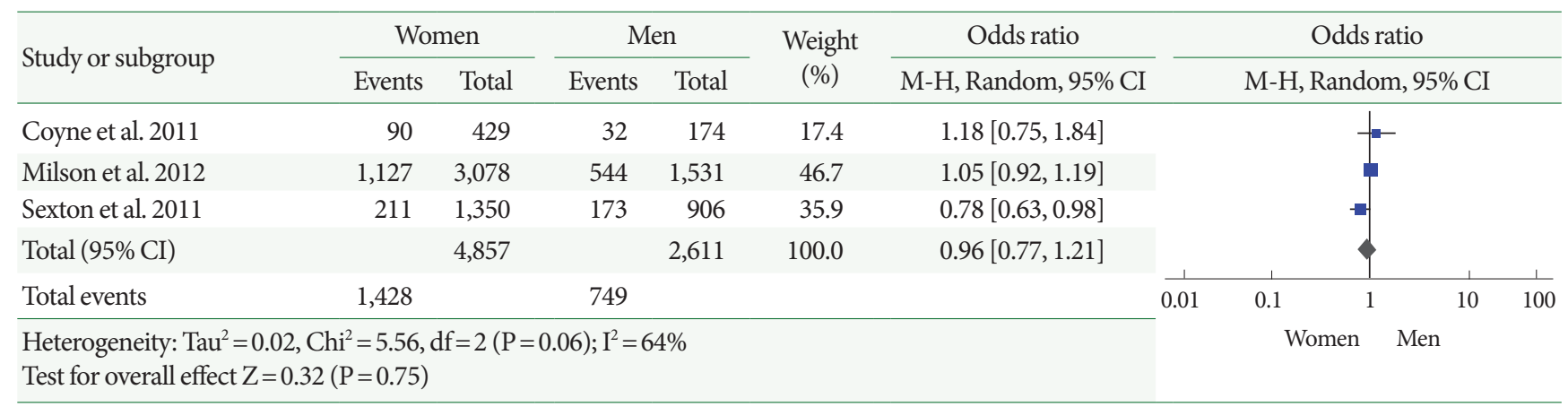

Fig. 2. Depression and overactive bladder according to sex: a meta-analysis. M-H, Mantel-Haenszel; CI, confidence interval; df, degrees of freedom.

\begin{tabular}{|c|c|c|c|c|c|c|c|c|c|c|c|}
\hline \multirow{3}{*}{$\begin{array}{l}\text { Study or subgroup } \\
\text { Coyne et al. } 2011\end{array}$} & \multicolumn{2}{|c|}{ Women } & \multicolumn{2}{|c|}{ Men } & \multirow{3}{*}{$\begin{array}{c}\begin{array}{c}\text { Weight } \\
(\%)\end{array} \\
15.9\end{array}$} & \multirow{3}{*}{$\begin{array}{c}\text { Odds ratio } \\
\text { M-H, Random, } 95 \% \text { CI } \\
1.65[1.30,2.10]\end{array}$} & \multirow{2}{*}{\multicolumn{5}{|c|}{$\begin{array}{c}\text { Odds ratio } \\
\text { M-H, Random, 95\% CI }\end{array}$}} \\
\hline & \multirow{2}{*}{$\begin{array}{c}\text { Events } \\
533\end{array}$} & \multirow{2}{*}{\begin{tabular}{r|} 
Total \\
891
\end{tabular}} & \multirow{2}{*}{$\begin{array}{c}\text { Events } \\
181\end{array}$} & \multirow{2}{*}{$\begin{array}{r}\text { Total } \\
382\end{array}$} & & & & & & & \\
\hline & & & & & & & & & \multirow{3}{*}{\multicolumn{2}{|c|}{ 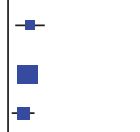 }} & \\
\hline Milson et al. 2012 & 1,472 & 3,036 & 567 & 1,512 & 61.0 & $1.57[1.38,1.78]$ & & & & & \\
\hline Sexton et al. 2011 & 310 & 1,320 & 161 & 889 & 23.0 & $1.39[1.12,1.72]$ & & & & & \\
\hline Total $(95 \%$ CI $)$ & & 5,247 & & 2,783 & 100.0 & $1.54[1.40,1.70]$ & & & 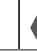 & & \\
\hline Total events & \multicolumn{2}{|l|}{2,315} & 909 & & & & \multirow[t]{2}{*}{0.02} & \multirow[t]{2}{*}{0.1} & \multirow{2}{*}{ en } & 10 & \multirow[t]{2}{*}{50} \\
\hline $\begin{array}{l}\text { Heterogeneity: } \mathrm{Chi}^{2} \\
\text { Test for overall effec }\end{array}$ & $\begin{array}{l}2(\mathrm{P}=0 . \\
<0.000\end{array}$ & $\begin{array}{l}1) ; I^{2}=0 \\
1)\end{array}$ & & & & & & & & Men & \\
\hline
\end{tabular}

Fig. 3. Anxiety and overactive bladder according to sex: a meta-analysis. M-H, Mantel- Haenszel; CI, confidence interval; df, degrees of freedom.

urge incontinence increased with age, and in men its frequency primarily increased after 64 years [4].

A cross-sectional study of 1,272 individuals with $\mathrm{OAB}$ aged 40-64 years concluded that men with OAB were significantly more likely than women to report an impact on their daily work life. This effect was primarily observed in men reporting $\mathrm{OAB}$ with incontinence. In this study, depression was more commonly found in women with incontinence (37.9\%) than in women without incontinence (21\%). In men, symptoms of depression were experienced by $47.5 \%$ of the subjects with incontinence versus $24.5 \%$ of those without incontinence [17].

Three articles were included in the meta-analysis [13,14,21], with a total of 7,468 participants in whom depression was evaluated and 8,030 participants in whom anxiety was evaluated. Men were considerably more likely than women to have anxiety related to $\mathrm{OAB}(\mathrm{OR}, 1.54 ; 95 \% \mathrm{CI}, 1.40-1.73)$, and there was no difference with respect to depression between men and women (OR, 0.96; 95\% CI, 0.77-1.21) (Figs. 2, 3).

\section{DISCUSSION}

All studies included in this systematic review and meta-analysis found that $\mathrm{OAB}$ was associated with increased rates of depression and/or anxiety. According to the World Health Organization, depressive disorders are important causes of health disabilities [22]. Moreover, anxiety is the most prevalent psychiatric disorder in the United States, affecting 18\% of the overall population [6]. Depression and anxiety can be characterized as a set of symptoms that may arise in a variety of medical conditions, including posttraumatic stress disorder, dementia, schizophrenia, alcoholism, and clinical diseases, and may also occur in response to stressful situations or in adverse social and economic circumstances [23]. Depression and anxiety are also associated with chronic illnesses such as OAB.

The association between affective disorders and symptoms of the urinary tract has been described since 1964 [24]. More recently, a combination of mental disorders has been proposed to be caused by some urinary symptoms [25]. One possible explanation for this association is that the social impact of $\mathrm{OAB}$ re- 
duces the functional capacity of the individual, generating stress, which leads to anxiety and depression.

Additionally, some evidence indicates that urinary and affective symptoms share common biological pathways, which could explain their co-occurrence, but the exact nature of the association of $\mathrm{OAB}$ with anxiety and depression remain unknown [26].

Although a previous study concluded that there was no causal relationship between personality traits and urogynecologic diseases [27], it is reasonable to assume that an individual's perceptions of incontinence might influence his or her coping strategies for dealing with urinary symptoms. This systematic review found that urge incontinence was correlated with worse depression and anxiety scores. $\mathrm{OAB}$ with urge incontinence was also associated with more severe anxiety $[18,19]$ and depression $[4,15,17]$. Depression was closely related to urge incontinence, which was the main cause of dissatisfaction $[8,12$ $17,20]$. The fatigue resulting from sleep interrupted by nocturia also appeared to contribute to feelings of depression and isolation at home [13].

Anxiety was likewise related to OAB. Participants with 'wet' $\mathrm{OAB}$ were significantly more likely than those with 'dry' $\mathrm{OAB}$ to express worry about having accidents and concerns about participating in activities outside of the home because of their bladder symptoms, causing stress and anxiety. In addition, those with 'wet' OAB were significantly more likely to report that these bladder symptoms were a source of great concern and made them feel uncomfortable in social situations than those with 'dry' OAB [16].

The results of this meta-analysis do not support the commonly held belief that women are considerably more likely than men to have depression related to $\mathrm{OAB}[5,16]$. There was no difference between men and women regarding depression. Women are more susceptible to develop OAB symptoms than men. Additionally, they tend to have more depression and anxiety than the male population $[4,12]$. Most previous articles have stated that women are more susceptible to depression and anxiety associated with OAB [13-16,21]. Cultural and educational issues can influence the vulnerability of women regarding these aspects of health [5,13-18,21]. In addition, anatomical differences may increase the risk of urge incontinence as an expression of $\mathrm{OAB}$ among women compared with men, which could be associated with higher levels of anxiety and depression. In fact, $\mathrm{OAB}$ with urge incontinence was associated with more severe anxiety $[19,20]$ and depression $[5,16,18]$. Depression was identified as a major cause of dissatisfaction among patients with urge incontinence [12-18,21]. Despite this, in this metaanalysis, we found that men were considerably more likely than women to have anxiety related to $\mathrm{OAB}$. In a study included in this systematic review, but not included in the meta-analysis, men were significantly more likely than women to report that $\mathrm{OAB}$ with incontinence had an impact on their daily work life, including worries about interrupting meetings (38\% of men vs. $22 \%$ of women), decisions about location and hours ( $21 \%$ of men vs. $8 \%$ of women) and voluntary termination or early retirement ( $27 \%$ of men vs. $4 \%$ of women). Among individuals affected by $\mathrm{OAB}$ without incontinence, the differences in the rates reported by men and women for each of these parameters were less marked [17].

This is the first meta-analysis to investigate the relationship between $\mathrm{OAB}$ and anxiety and depression in relation to sex, and an important association was found between urinary $(\mathrm{OAB})$ and affective symptoms (depression and anxiety).

The studies included in this systematic review were conducted in heterogeneous populations. As the clinical presentation of anxiety and depression in men and women diverges significantly, and only 2 studies were limited to women [19,20], it is not possible to develop general advice applicable to women on the basis of our findings. The questionnaires and scores used to assess depression and anxiety in the included studies differed significantly. For this reason, only 3 articles could be included in the meta-analysis. Future studies with homogeneous populations and questionnaires could contribute to more accurate results.

Additionally, $\mathrm{OAB}$ symptoms are prevalent among patients with psychological problems, and psychological problems are prevalent among patients with OAB. Further studies analyzing the differences in these patient subgroups could conceivably shed light on the nature of the association. From a methodological point of view, the studies included in this review were primarily quantitative. The variables of $\mathrm{OAB}$, depression, and anxiety were screened in order to find correlations among urinary symptoms and anxiety and depression. Qualitative research in this area could increase our knowledge about the experiences of these patients and the possible ramifications of urinary, depressive, or anxious symptoms in their life. Nonetheless, the articles reviewed highlight the need for the psychotherapeutic aspects of the treatment of $O A B$ to be better investigated, as psychotherapy led to significant improvements in patients with urgency, incontinence, and nocturia, although it did not 
lead to improvements in patients with complaints of frequency [28]. The search for treatment to address this problem is affected by the coping strategies of these patients in relation to their symptoms. Psychological factors can have a profound impact on the management of $\mathrm{OAB}$, potentially influencing treatmentseeking behavior, satisfaction with therapy, and persistence with therapy, all of which could potentially be examined. Further research is required in patients with $\mathrm{OAB}$ symptoms, anxiety, and depression to determine how best to provide psychological support in such cases.

In conclusion, this systematic review and meta-analysis found an association of $\mathrm{OAB}$ with higher levels of anxiety and depression. Incontinence $\mathrm{OAB}$ was closely related to anxiety and depression. Men were considerably more likely than women to have anxiety related to OAB. There was no difference between men and women in terms of depression related to $\mathrm{OAB}$ symptoms. This review highlights the need to investigate the correlation between depression and anxiety in patients with OAB.

\section{ACKNOWLEDGMENTS}

We are grateful to the Coordenação de Aperfeiçoamento de Pessoal de Nivel Superior (CAPES) for supporting this study with a postgraduate grant to one of the authors (IGRM).

\section{REFERENCES}

1. Abrams P, Andersson KE, Birder L, Brubaker L, Cardozo L, Chapple $\mathrm{C}$, et al. Fourth International Consultation on Incontinence Recommendations of the International Scientific Committee: Evaluation and treatment of urinary incontinence, pelvic organ prolapse, and fecal incontinence. Neurourol Urodyn 2010;29:213-40.

2. Haylen BT, de Ridder D, Freeman RM, Swift SE, Berghmans B, Lee J, et al. An International Urogynecological Association (IUGA)/International Continence Society (ICS) joint report on the terminology for female pelvic floor dysfunction. Neurourol Urodyn 2010; 29:4-20.

3. Kelleher CJ, Cardozo LD, Toozs-Hobson PM. Quality of life and urinary incontinence. Curr Opin Obstet Gynecol 1995;7:404-8.

4. Liberman JN, Hunt TL, Stewart WF, Wein A, Zhou Z, Herzog AR, et al. Health-related quality of life among adults with symptoms of overactive bladder: results from a U.S. community-based survey. Urology 2001;57:1044-50.

5. Stewart WF, Van Rooyen JB, Cundiff GW, Abrams P, Herzog AR,
Corey $\mathrm{R}$, et al. Prevalence and burden of overactive bladder in the United States. World J Urol 2003;20:327-36.

6. Chiaffarino F, Parazzini F, Lavezzari M, Giambanco V; Gruppo Interdisciplinare di Studio Incontinenza Urinaria (GISIU). Impact of urinary incontinence and overactive bladder on quality of life. Eur Urol 2003;43:535-8.

7. Vrijens D, Drossaerts J, van Koeveringe G, Van Kerrebroeck P, van Os J, Leue C. Affective symptoms and the overactive bladder - a systematic review. J Psychosom Res 2015;78:95-108.

8. Wells KB, Stewart A, Hays RD, Burnam MA, Rogers W, Daniels M, et al. The functioning and well-being of depressed patients. Results from the Medical Outcomes Study. JAMA 1989;262:914-9.

9. Jadad AR, Moore RA, Carroll D, Jenkinson C, Reynolds DJ, Gavaghan DJ, et al. Assessing the quality of reports of randomized clinical trials: is blinding necessary? Control Clin Trials 1996;17:112.

10. Review Manager (RevMan) [Computer program]. Version 5.3. Copenhagen: The Nordic Cochrane Centre, The Cochrane Collaboration, 2014.

11. Hulley SB, Cummings ST, Browner WS, Grady DG, Newman TB. Outlining clinical research. 4th ed. Artmed: Porto Alegre; 2015.

12. Nicolson P, Kopp Z, Chapple CR, Kelleher C. It's just the worry about not being able to control it! A qualitative study of living with overactive bladder. Br J Health Psychol 2008;13(Pt 2):343-59.

13. Milsom I, Kaplan SA, Coyne KS, Sexton CC, Kopp ZS. Effect of bothersome overactive bladder symptoms on health-related quality of life, anxiety, depression, and treatment seeking in the United States: results from EpiLUTS. Urology 2012;80:90-6.

14. Sexton CC, Coyne KS, Thompson C, Bavendam T, Chen CI, Markland A. Prevalence and effect on health-related quality of life of overactive bladder in older americans: results from the epidemiology of lower urinary tract symptoms study. J Am Geriatr Soc 2011; 59:1465-70.

15. Ikeda Y, Nakagawa H, Ohmori-Matsuda K, Hozawa A, Masamune Y, Nishino Y, et al. Risk factors for overactive bladder in the elderly population: a community-based study with face-to-face interview. Int J Urol 2011;18:212-8.

16. Coyne KS, Sexton CC, Irwin DE, Kopp ZS, Kelleher CJ, Milsom I. The impact of overactive bladder, incontinence and other lower urinary tract symptoms on quality of life, work productivity, sexuality and emotional well-being in men and women: results from the EPIC study. BJU Int 2008;101:1388-95.

17. Irwin DE, Milsom I, Kopp Z, Abrams P, Cardozo L. Impact of overactive bladder symptoms on employment, social interactions and emotional well-being in six European countries. BJU Int 2006; 
97:96-100.

18. Teloken C, Caraver F, Weber FA, Teloken PE, Moraes JF, Sogari PR, et al. Overactive bladder: prevalence and implications in Brazil. Eur Urol 2006;49:1087-92.

19. Lim JR, Bak CW, Lee JB. Comparison of anxiety between patients with mixed incontinence and those with stress urinary incontinence. Scand J Urol Nephrol 2007;41:403-6.

20. Alves AT, Jácomo RH, Gomide LB, Garcia PA, Bontempo AP, Karnikoskwi MG. Relationship between anxiety and overactive bladder syndrome in older women. Rev Bras Ginecol Obstet 2014; 36:310-4.

21. Coyne KS, Sexton CC, Kopp ZS, Ebel-Bitoun C, Milsom I, Chapple C. The impact of overactive bladder on mental health, work productivity and health-related quality of life in the UK and Sweden: results from EpiLUTS. BJU Int 2011;108:1459-71.

22. Ustün TB, Ayuso-Mateos JL, Chatterji S, Mathers C, Murray CJ. Global burden of depressive disorders in the year 2000. Br J Psychiatry 2004;184:386-92.
23. Brazil, ISPS, Ponde MP. Anxious and depressive symptoms and their correlation with pain severity in patients with peripheral neuropathy. Rev. Psiquiatr Rio Gd Sul 2009;31:24-31.

24. Engel WJ. Uropsychiatry. J Mich State Med Soc 1964;63:273-7.

25. Cortes E, Sahai A, Pontari M, Kelleher C. The psychology of LUTS: ICI-RS 2011. Neurourol Urodyn 2012;31:340-3.

26. Hirayama A, Torimoto K, Mastusita C, Okamoto N, Morikawa M, Tanaka N, et al. Risk factors for new-onset overactive bladder in older subjects: results of the Fujiwara-kyo study. Urology 2012;80: 71-6.

27. Bodden-Heidrich R, Beckmann MW, Libera B, Rechenberger I, Bender HG. Psychosomatic aspects of urinary incontinence. Arch Gynecol Obstet 1999;262:151-8.

28. Macaulay AJ, Stern RS, Holmes DM, Stanton SL. Micturition and the mind: psychological factors in the aetiology and treatment of urinary symptoms in women. Br Med J (Clin Res Ed) 1987;294: 540-3. 